\title{
The GENACIS project: a review of findings and some implications for global needs in women-focused substance abuse prevention and intervention
}

\author{
This article was published in the following Dove Press journal: \\ Substance Abuse and Rehabilitation \\ 27 January 2012 \\ Number of times this article has been viewed
}

\section{Sharon C Wilsnack \\ Department of Clinical Neuroscience, University of North Dakota School of Medicine and Health Sciences, Grand Forks, ND, USA}

\begin{abstract}
Gender, Alcohol, and Culture: An International Study (GENACIS) is a collaborative study of gender-related and cultural influences on alcohol use and alcohol-related problems of women and men. Members conduct comparative analyses of data from comparable general population surveys in 38 countries on five continents. This paper presents GENACIS findings that (1) age-related declines in drinking are uncommon outside North America and Europe; (2) groups of women at increased risk for hazardous drinking include women who cohabit, women with fewer social roles, more highly educated women in lower-income countries, and sexual minority women in North America; (3) heavier alcohol use shows strong and cross-culturally consistent associations with increased likelihood and severity of intimate partner violence; and (4) one effect or accompaniment of rapid social, economic, and gender-role change in traditional societies may be increased drinking among formerly abstinent women. These findings have potentially important implications for women-focused intervention and policy. Substance abuse services should include attention to middle-aged and older women, who may have different risk factors, symptoms, and treatment issues than their younger counterparts. Creative, targeted prevention is needed for high-risk groups of women. Programs to reduce violence between intimate partners must include attention to the pervasive role of alcohol use in intimate partner aggression. Social and economic empowerment of women, together with social marketing of norms of abstention or low-risk drinking, may help prevent increased hazardous alcohol use among women in countries undergoing rapid social change. Greater attention to effects of gender, culture, and their interactions can inform the design of more effective prevention, intervention, and policy to reduce the substantial global costs of alcohol abuse in both women and men.
\end{abstract}

Keywords: GENACIS, women, alcohol, substance abuse, international, intervention, prevention

\section{Introduction}

GENACIS (Gender, Alcohol, and Culture: An International Study) is an international study of gender, culture, and alcohol use led by research partners from the USA, Australia, Canada, Denmark, and Switzerland, with additional members from more than 40 countries in every continent except Antarctica. The overall goal of the GENACIS project is to understand how gender, culture, and their interactions influence the alcohol consumption and alcohol-related problems of women and men. GENACIS has received funding from the US National Institute on Alcohol Abuse and Alcoholism/National Institutes of Health, the World Health Organization, the European 
Commission, the German Federal Ministry of Health, the Pan American Health Organization, and Swiss national funds. Support for individual country surveys is provided by government agencies and other national sources. This article describes the history of the GENACIS project and reviews findings from recent comparative analyses of GENACIS data. Although GENACIS analyses are designed to learn more about cultural and gender-related influences on alcohol use among both men and women, this paper originated as an invited presentation at an international conference on women and substance abuse. For this reason, the final section of the paper deals primarily with possible implications of GENACIS findings for women-focused substance abuse treatment, prevention, and policy.

A note about terminology: In this paper the term "gender" refers to socially constructed roles, behaviors, and attributes that a given society considers appropriate for men and for women, and the term "sex" refers to biological and physiological attributes that define men and women. ${ }^{1}$ Sex differences between men and women vary relatively little across societies, whereas gender attributes can and do vary greatly across societies. It follows that GENACIS research has a primary focus on gender and on the powerful influence of societal definitions of masculinity and femininity on the drinking behavior and drinking-related problems of men and women in diverse cultures.

\section{GENACIS: a brief history International Research Group on Gender and Alcohol and GENACIS}

During the 1970s and 1980s, research on women's alcohol and drug use was increasing in North America and Europe. One of the earliest large-scale studies of women's drinking was the National Study of Health and Life Experiences of Women (NSHLEW), a National Institute on Alcohol Abuse and Alcoholism-funded longitudinal study of drinking and problem drinking in a national sample of US women, who were interviewed every 5 years between 1981 and 2001.2-5 In the late 1980s, Czech alcohol researcher Luděk Kubička and colleagues, and Swedish alcohol researcher Fredrik Spak and colleagues began using the NSHLEW questionnaire in studies of Czech and Swedish women's drinking. ${ }^{6,7}$ This threeway collaboration expanded into the International Research Group on Gender and Alcohol (IRGGA), organized at the 1993 annual symposium of the international Kettil Bruun Society for Social and Epidemiological Research on Alcohol in Krakow, Poland. Beginning with 13 researchers from nine countries, IRGGA now has more than 150 members from more than 40 countries and meets annually in conjunction with the Kettil Bruun Society's symposium.

During IRGGA's early years, members conducted and published cross-national analyses of the drinking and related problems of women and men, using existing survey data sets. ${ }^{89}$ However, the limited set of comparable measures available in the existing data sets was recognized as a major impediment to conducting comparative analyses. In 1998, IRGGA members began developing the multinational GENACIS project, designed to collect and analyze data from new surveys of women and men in many countries, using comparable questions and survey methods. ${ }^{10} \mathrm{~A}$ major challenge for the new project was choosing a set of measures of alcohol consumption and alcohol-related problems that was manageable in length but broad and diverse enough to capture accurately the considerable variability in typical drinking patterns across the GENACIS countries. This variability included, for example, the traditional "wet" vs "dry" drinking cultures of European countries, the former (exemplified traditionally by Mediterranean countries) characterized by low abstention rates, frequent relatively moderate drinking (often with meals), and low rates of acute alcohol problems, the latter (exemplified traditionally by Nordic countries) characterized by high rates of abstention, infrequent but very heavy or binge drinking, and high rates of acute alcohol-related problems such as alcohol-related violence and alcohol poisoning, ${ }^{11}$ as well as culture-specific drinking patterns, such as "fiesta drinking" in many Latin American countries ${ }^{12}$ and the common use of unrecorded, locally produced alcoholic beverages in many countries..$^{13}$ To ensure that the common GENACIS questionnaire was appropriate for these varying cultural drinking patterns, working groups of GENACIS members representing many countries spent more than 3 years reviewing and evaluating potential measures. The final instrument, reached by consensus, contained both beverage-specific and generic measures of drinking frequency, quantity per occasion, maximum consumption, heavy episodic ("binge") drinking, intoxication, and a comprehensive set of questions about both acute and chronic alcohol-related problems. Questions about drinking contexts and companions allowed assessment of culturally variable drinking patterns and settings (eg, drinking with meals, street drinking), and administration of the quantity, frequency, variability, and maximum questions for any commonly used, locally produced alcoholic beverage permitted assessment of "unrecorded" (surrogate, illicit) alcohol use in addition to use of commercially produced beer, wine, and spirits. 


\section{GENACIS measures}

The GENACIS questionnaire, completed in 2001, includes detailed questions about alcohol consumption, alcoholrelated problems (including all questions from the internationally validated Alcohol Use Disorders Identification Test), ${ }^{14}$ drinking contexts and companions, and social pressures to reduce (or increase) drinking, as well as questions about demographic characteristics, social roles, violence and victimization, physical and emotional health, use of illicit drugs, and intimate relationships, including intimate partner violence. Detailed guidelines were developed for translation and back-translation of the questionnaire. All surveys conducted after November 2001, when the GENACIS questionnaire was finalized, included all questions from the common questionnaire, with a few (rare) exceptions of specific questions judged by survey leaders and staff to be culturally inappropriate for their country.

In addition to the many individual-level variables measured by the GENACIS questionnaire, a number of societallevel characteristics are also measured. Archival measures are used for some societal-level variables, such as economic development ${ }^{15}$ and gender equality. ${ }^{16}$ Others, such as societallevel drinking patterns (eg, abstention rates or rates of heavy episodic or "binge" drinking) are estimated by aggregating the responses of all respondents in each survey. The de-identified data from participating countries are sent to a centralized data base at the Addiction Info Switzerland Research Institute (formerly the Swiss Institute for the Prevention of Alcohol and Drug Problems) in Lausanne, Switzerland.

\section{GENACIS countries}

As of November 2011, the GENACIS project included general population surveys of women's and men's drinking behavior in 38 countries: Argentina, Australia, Austria, Belize, Brazil, Canada, Costa Rica, Czech Republic, Denmark, Dominican Republic, Finland, France, Germany, Great Britain, Guyana, Hungary, Iceland, India, Ireland, Isle of Man, Israel, Italy, Japan, Kazakhstan, Mexico, Netherlands, New Zealand, Nicaragua, Nigeria, Norway, Peru, Spain, Sri Lanka, Sweden, Switzerland, Uganda, Uruguay, and USA. Unlike many international alcohol research projects, which include primarily European and North American countries, support from the World Health Organization and the Pan American Health Organization has allowed GENACIS to partner with lower- and middle-income countries in Africa, Asia, and Latin America, yielding a rich and diverse range of cultures for comparative analyses. Funding is currently being sought for additional GENACIS surveys in several countries, including
China, Guatemala, Honduras, Kenya, Malawi, Panama, and Thailand. Although the GENACIS surveys differ somewhat in sampling frame (most are national, some regional), sampling method (most are probability samples), and modes of administration (most are face-to-face), they are more similar than data sets for most other multinational studies.

\section{GENACIS analyses and publications}

Many research questions have been examined in analyses of GENACIS data. These questions include how drinking is linked to various types of harmful behavior, to informal social pressures to control drinking, and to particular qualities of intimate relationships, including intimate partner violence; and how drinking and its effects are modified by socioeconomic conditions, social status and social roles, and the physical and social contexts in which drinking occurs. Many analyses have used hierarchical linear modeling and other advanced statistical methods to evaluate how societal-level variables (eg, economic development and gender equality) influence and modify associations among individual-level variables (eg, associations between alcohol consumption and intimate partner violence or other harmful behavior).

In November 2011, GENACIS publications included seven books and research monographs, two special journal issues, and more than 100 peer-reviewed journal articles and book chapters. A special issue of the journal Alcohol and Alcoholism ${ }^{17}$ contained six papers based on data from European Union countries, and a special section of Contemporary Drug Problems ${ }^{18}$ contained five papers on associations between informal social control and alcohol in multiple GENACIS countries. A book published by the World Health Organization $(\mathrm{WHO})^{19}$ reported findings from eight lower- and middleincome countries whose GENACIS surveys were funded by WHO, and a book published by the Pan American Health Organization in 2008 in English and in 2010 in Spanish ${ }^{20,21}$ reported analyses of associations between alcohol use and intimate partner aggression, using data from eight Latin American countries, Canada, and the United States.

Additional information about the development, methods, and products of the GENACIS project can be found in Taylor et al, ${ }^{22}$ Wilsnack et al, ${ }^{23}$ and the project's two websites: http:// www.med.und.edu/depts/irgga (click on GENACIS), and http://www.genacis.org.

\section{GENACIS findings Gender- and age-related drinking patterns} Two well-established demographic correlates of drinking patterns are gender and age. Studies using ethnographic, 
historical, and epidemiological methods have found that men in all cultures and historical periods studied have consumed more alcohol and experienced more alcohol-related problems than women. ${ }^{24,25}$ Research in Europe and North America has generally shown that alcohol use, and heavy use in particular, is highest in youth and declines with increasing age. ${ }^{26,27}$

A 2009 GENACIS paper examined associations of gender and age with patterns of abstention, drinking, and heavier drinking, using data from 35 GENACIS countries. ${ }^{23}$ The analyses found the expected gender differences: in all 35 countries men were more likely than women to be drinkers and to drink more heavily. However, although men in all countries drank more than women, the size of the gender difference varied greatly across countries. For example, the male:female ratio for current drinkers (nonabstainers) ranged from 1.00 in New Zealand and Norway to 12.33 in India, and the male:female ratio for high volume drinking (more than 8468 grams of ethanol per year) among drinkers ranged from 1.34 in Nigeria to 20.17 in Hungary. The fact that men in all countries drank more than women suggests that there is a biological component to this gender difference, most likely related to physiological sex differences in body weight, body composition, and alcohol metabolism; ${ }^{28,29}$ these biological sex differences probably also contribute to women's greater vulnerability to both acute alcohol effects ${ }^{30}$ and longer-term medical effects, eg, alcohol-related liver disease. ${ }^{31}$ However, the large variation in the magnitude of the gender difference across countries suggests that cultural influences (eg, gender roles that define how men and women are expected or allowed to drink) are also important, interacting with and modifying biologically based sex differences in alcohol consumption. ${ }^{32}$

Although the expected gender differences were found in all 35 GENACIS countries, the data did not support the expected age differences. In fact, the expected pattern - high levels of drinking in youth followed by declines in middle and older age - occurred mainly in countries in Europe and North America. In other parts of the world, drinking either did not decline consistently with age or actually increased with age, perhaps because drinking in some cultures is traditionally a prerogative of older age, associated with higher status or seniority. ${ }^{33,34}$ The striking differences among age-related drinking patterns in different parts of the world indicate that the effects of age on alcohol consumption are socially and culturally complex, and cannot be predicted simply from biological aging processes.

\section{High-risk groups}

A number of GENACIS papers have reported findings about population subgroups with higher rates of heavy drinking and/or drinking-related problems. In a study of 19 GENACIS countries, Li and colleagues ${ }^{35}$ found that women drinkers who cohabited (lived with partners to whom they were not legally married) were more likely to engage in heavy episodic drinking (five or more drinks in a drinking day) than married women of the same age and education. Grittner and colleagues $^{36}$ conducted multilevel analyses of associations of men's and women's drinking patterns with individual-level socioeconomic status (measured by educational level) and societal-level economic development. Of all combinations of gender (male vs female), individual socioeconomic status (high vs low education), and country-level economic development (high vs low Gross Domestic Product), more highly educated women in lower-income countries were the most likely to engage in heavy episodic drinking. A third high-risk group was identified by Kuntsche and colleagues ${ }^{37}$ in a study of social roles (paid employment, marriage or other partnership, and parenthood) and drinking in ten industrialized GENACIS countries. These investigators found that women with fewer social roles had higher rates of heavier drinking than women who held more social roles. A subsequent study by Kuntsche and colleagues ${ }^{38}$ found that associations between multiple roles (motherhood, partnerhood, and paid labor) and women's alcohol use varied between countries with high vs low gender-income equity: in countries with high genderincome equity, partnered mothers who engaged in paid labor drank less alcohol per occasion, whereas alcohol use was higher among partnered mothers working for pay in countries with lower gender-income equity. Finally, Bloomfield and colleagues $^{39}$ analyzed associations between sexual minority status and drinking in 14 GENACIS countries. Self-reports of same-sex sexual partners were used as a proxy for sexual minority status. Sexual minority status was associated with heavier drinking only among women in Canada and the United States; there were no significant associations between reports of same-sex partners and drinking patterns among men or among women in countries outside North America.

\section{Alcohol and intimate partner violence}

One important focus of GENACIS research has been associations between alcohol use and intimate partner violence (IPV). The GENACIS questionnaire includes a detailed set of questions about both women's and men's experiences of physical partner aggression, as both victim and aggressor. Because women's reports of aggressive behavior toward 
their intimate partners are difficult to interpret - in particular whether women initiated the aggressive behavior without provocation or engaged in it in self-defense - the focus in this review of GENACIS findings on partner aggression is on connections between alcohol use and men's experiences as aggressors and women's experiences as victims. Information on the reciprocal pattern - women as aggressors and men as victims - is available elsewhere. ${ }^{20}$ In general, associations between alcohol use and female-to-male aggression were similar to those described below for male-to-female aggression: female aggression and male victimization were both related to drinking (vs abstention) and to heavier drinking per occasion. Ratings of feelings of anger, fear, upset, and perceptions that the aggression was life-threatening indicated that male-to-female aggression was perceived as more severe and life-threatening, and female victims in all countries were more likely than male victims to seek medical attention.

A comparative study of alcohol use and physical partner aggression in eight Latin American countries, Canada, and the United States was reported in Unhappy Hours: Alcohol and Partner Aggression in the Americas, published by the Pan American Health Organization. ${ }^{20,21}$ The study's major findings were remarkably consistent across the ten countries, despite differences in culture, economic development, and gender equality. Across all ten countries, drinkers were more likely than abstainers to report physical partner aggression. Among drinkers, those who reported heavy episodic drinking (five or more drinks in a drinking day) at least once in the past year were consistently more likely to report partner aggression. Thus, in all ten countries men who engaged in heavy episodic drinking were significantly more likely to engage in physical aggression toward their female partners, than men who did not report heavy episodic drinking; in all ten countries women who engaged in heavy episodic drinking were more likely to be victims of physical partner aggression.

There was no consistent relationship between frequency of drinking and risks of partner aggression, but persons who reported partner aggression reported consuming larger numbers of drinks on drinking days and a larger total number of drinks per year. Heavy drinking per occasion emerged as the most important alcohol-related risk factor for incidents of physical partner aggression.

Additional analyses compared drinking at the time of the aggressive incident and partners' ratings of the severity of aggression - how life-threatening the aggression was perceived to be. In all ten countries, incidents of partner aggression in which one (usually the male) or both partners were drinking at the time of the aggression were rated as significantly more severe and life-threatening than incidents that did not involve alcohol. The consistency of these patterns was quite striking across ten countries that varied considerably in their rates of both alcohol use and partner violence. Subsequent analyses included seven countries in the Americas as well as other countries in Africa, Asia, and Eastern Europe; these analyses included all four gender $\times$ aggressor-victim-role combinations (female victim, female aggressor, male aggressor, male victim) ${ }^{40} \mathrm{As}$ in the previous analyses, ratings of severity were significantly higher for aggressive incidents in which one or both partners were drinking than for incidents in which neither partner was drinking. The positive association between drinking and severity of aggression did not differ significantly for women vs men or by country.

In 2011, funding was received to conduct a qualitative study of alcohol and partner violence. ${ }^{41}$ The study will involve in-depth focus group interviews in eleven countries (including lower-resourced countries in Africa, Asia, and Latin America) about how both lay persons and professionals in those countries perceive associations between alcohol use and IPV. This is a rare and valuable opportunity to bring both qualitative and quantitative data to bear on trying to understand the widespread and destructive interactions between heavy alcohol use and experiences of intimate partner violence.

\section{Social change and gendered drinking}

A final area of interest is the effects of rapid social change on women's alcohol use and related problems. In 2003 GENACIS members presented a symposium titled "Social Change and Gendered Drinking” in honor of Dr Luděk Kubička, a leading alcohol researcher in the Czech Republic and a founding member of IRGGA and GENACIS. Kubička conducted unique longitudinal analyses of changes in women's and men's drinking after the "Velvet Revolution" of 1989, which ended the 41-year Communist era in Czechoslovakia.,42 Other papers in the 2003 symposium, subsequently published in the journal Addiction, ${ }^{43}$ included studies of women's and men's drinking during the 1990-2005 economic crisis in Argentina $^{44}$ and after major social and political change in reunited Germany ${ }^{45}$ and in Poland. ${ }^{46}$ Findings from the studies of reunited Germany and of Poland during the transition from Communism both contained some evidence suggesting gender divergence in drinking (increased drinking among men and/or decreased drinking among women). One possible interpretation is that in some crisis situations women 
may lose power and status, one indicator of which is reduced access to alcohol. ${ }^{47}$ In contrast to these suggestions of gender divergence, Kubička's own research found gender convergence of drinking during the transition from Communism in Prague: men's drinking increased by $16 \%$ while women's drinking increased by one-third - twice as large as men's increase - with the greatest increase among newly economically active, entrepreneurial women. ${ }^{6,42}$ Room, ${ }^{47}$ discussing papers from the symposium, concluded that "studying who changes their drinking by how much in times of social change shines new light on our understanding of gender roles and drinking" (p. 1801).

GENACIS members' interests in the effects of social change were further strengthened by the November 2010 conference, "Alcohol Epidemiology and Evidence-Based Policy: Translating Research into Effective Prevention, Treatment, and Policy," in Kampala, Uganda. Co-sponsored by GENACIS, this historic meeting was the first intercontinental alcohol research conference held in sub-Saharan Africa. Papers presented at the Kampala conference noted the high abstention rates (90\% or higher in some countries) among women in most African countries. ${ }^{48}$ Based on experiences in other countries with a tradition of female abstention, African researchers and policymakers are concerned that women's drinking could increase substantially as a result of economic, social, and gender-role changes. As one example, in Korea the percentage of adult women who drink increased from $32 \%$ in 1989 to $80 \%$ in 2007 , nearly equaling the rate of men (in the mid-90\%s). ${ }^{49}$ Participants in the Kampala conference were eager to find ways to avoid a similar increase in women's drinking in Africa, where economic development plus active efforts of the global alcohol industry to influence emerging alcohol policies in African countries ${ }^{50}$ could produce a rapid reversal of the traditional pattern of female abstention. Efforts are currently underway to obtain funding for follow-up surveys in India (Karnataka state) and Uganda, where the initial GENACIS surveys were conducted in 2003. ${ }^{51,52}$ Ten-year trend data in these countries would provide valuable insight into changes in women's and men's alcohol use that follow or accompany social, economic, and gender-role change.

\section{Implications for women-focused prevention, treatment, and policy} Services for middle-aged and older women

In many countries, including the US, prevention efforts and policies focus predominantly on high-risk drinking among youth. ${ }^{53,54}$ GENACIS findings that alcohol use did not decline with increasing age in most countries outside Europe and North America suggest that women-focused prevention and treatment approaches need to include attention to and services not only for younger but also for middle-aged and older women substance users. Middle-aged and older women who continue to drink, face physiological, age-related risks (eg, enhanced alcohol effects due to reduced body water, interactions between alcohol and prescription medications) as well as long-term cumulative effects of alcohol that may damage their health and longevity. Risk factors, symptoms of substance use disorders, and treatment issues may differ for older women compared with their younger counterparts. ${ }^{55}$ Furthermore, approaches to early identification and intervention, such as screening and brief intervention in primary medical care settings, should be especially sensitive to substance abuse in middle aged and older patients. Although gender- and age-sensitive treatment is a worthy ideal, limited resources available for any treatment in lowerincome countries may mean that this ideal is currently unattainable. Nonetheless, where resources become available and treatment systems develop, an awareness that alcohol-related problems affect persons across the lifespan may persuade developing substance abuse treatment programs to avoid a primary focus on youth, which characterizes many prevention and intervention programs in higher-income countries. ${ }^{56}$

\section{High-risk groups for targeted prevention}

GENACIS findings suggest some important high-risk groups for targeted substance abuse prevention and intervention. These include (1) women who are cohabiting (sometimes termed common-law marriages), (2) more highly educated women in lower-income countries, and (3) women who lack meaningful social roles. GENACIS data indicate that these subgroups of women show elevated rates of heavier drinking, but do not suggest specific prevention approaches that could reduce this elevated risk. Creative prevention researchers and practitioners might be able to craft prevention messages targeted to the characteristics of these subgroups. In addition, societal-level change that increases educational, employment, and other opportunities for women would benefit all women and might reduce the risks of hazardous drinking, particularly in groups (2) and (3). More specifically, findings reported above ${ }^{38}$ suggest that policies to improve the compatibility of motherhood and paid employment may reduce alcohol use in women with the multiple roles of motherhood, partnerhood, and paid employment. Finally, the higher rate 
of heavier drinking among more highly educated women in lower-income countries could mark the beginning of a diffusion process in which the "innovation" of heavier drinking is beginning with higher-status women, who have greater resources for purchasing alcohol and more drinking opportunities associated with work and social roles. According to Rogers' ${ }^{57}$ diffusion of innovation theory, innovations are first adopted by individuals or societies with higher socioeconomic status and upward social mobility, and then gradually adopted by other segments of the society. ${ }^{36} \mathrm{As}$ part of much-needed alcohol policy development in lowerincome countries it will be important to monitor consumption trends in population subgroups, such as women with higher socioeconomic status, to detect early signs of diffusion of hazardous drinking behaviors, and to implement policies to slow or reverse diffusion of these behaviors to other population subgroups.

Further research is needed to clarify the lack of significant associations between sexual minority status and drinking patterns among women outside North America. One possible reason for this lack is the relatively small number of women who reported female partners in many GENACIS countries, resulting in reduced statistical power. Another possible interpretation is a greater openness and stronger sense of community among lesbians and bisexual women in North America, leading to greater willingness to report same-sex relationships, and to more frequent socializing in group settings that include drinking opportunities. In any case, the significant associations between sexual minority status and heavier drinking among Canadian and US women suggest the need for more research on the etiology of these associations, and the need for awareness of these associations on the part of health care providers and others who serve sexual minority women. ${ }^{58,59}$

\section{Alcohol and intimate partner violence}

The consistent connections between heavier alcohol use and risks of intimate partner violence, across countries that differ in drinking patterns, gender roles, and IPV rates, suggest that IPV is likely to be an important treatment issue for many women substance abusers. Unfortunately in many countries, the services for substance abusing women and services for women living with partner violence are still seldom integrated or coordinated. Clearly, efforts are needed to increase awareness and cross-training of clinical staff, and coordination of substance abuse services and IPV services, so that affected women (and men) can receive needed services for these serious and interrelated problems. ${ }^{60}$ From the standpoint of prevention, the GENACIS findings suggest that programs that can reduce rates of substance abuse may also effectively reduce rates of IPV, and that any programs or policies designed to reduce this violence need to take into account the pervasive role of alcohol in the etiology of intimate violent behavior. ${ }^{20,21}$

\section{Social and economic change: effects on alcohol use and related problems}

GENACIS interests in gender, culture, and alcohol converge in the question of the likely effects on alcohol consumption of the social and economic change that is beginning to occur in many lower-resourced countries worldwide. Although traditional and historical differences in gender roles in these countries have largely limited problem drinking to men, ${ }^{23,25}$ many of these gender-role differences are declining and are likely to continue to decline. Some of the reasons are economic: by choice and by necessity women are increasingly engaging in paid employment outside the home, which gives them greater resources and opportunities to consume alcoholic beverages. Other changes in women's social roles enable them to engage in an increasing range of activities (eg, political and educational) that were once male privileges. The likely result is that alcohol consumption will become an increasingly routine activity for women in these countries, and thus increasing numbers of women will risk the adverse consequences of drinking. Continued abstention should be a valued and encouraged option for women. However, for women who do choose to drink, effective prevention and policies will need to find ways of encouraging women to drink more cautiously and responsibly than their male counterparts have done in the past. In fact, encouraging women to use alcohol more moderately, and to avoid the adverse consequences of men's heavier drinking, may be one way of empowering women as they expand their economic and social roles beyond the traditional roles of wife and mother.

Changes in gender roles are also likely to affect how some men drink, with potentially important consequences for women. For centuries, heavy drinking in traditional societies has been seen as both a symbol and an affirmation of male power. ${ }^{25,61}$ Amid twenty-first century challenges to male dominance and superiority in many areas of life, and amid the widespread economic uncertainties in many lower-resourced countries, some men may perceive heavy drinking and intoxication not merely as ways to dull negative feelings but also as a way to assert and demonstrate their 
strength and masculinity. One might expect this perception particularly in younger, socially-disadvantaged men who have few other sources of positive self-esteem. In effect, as gender-role differences become less absolute, some men may try to compensate by drinking more excessively. A challenge for prevention and policy is to find ways to encourage men to demonstrate their masculinity in more constructive ways than drinking heavily.

If these two changes occur together, countries undergoing social and economic change may have to deal with a third challenge: an increase in the frequency and severity of IPV. GENACIS findings discussed earlier indicate that heavy drinking by either or both partners increases the likelihood and the severity of IPV. Drinking by both partners can reduce the ability of both to recognize and curb the risks that conflicts, threats, and violence will get out of control. Heavy drinking by either or both partners will increase the likelihood that the drinking itself will become a source of tension and conflict in the relationship. If men drink more heavily in part to assert their masculine power, particularly toward alcohol-impaired partners, it is all the more likely that violence will result. ${ }^{40,60}$

A key question is how to persuade drinkers that alcohol is a poor way for men to demonstrate masculinity, a poor way for women to demonstrate gender equality, and a poor excuse for violence. It is clear that such persuasion cannot be achieved merely through simple educational approaches ${ }^{62}$ or by trying to frighten or shame drinkers, such as by warning labels. ${ }^{63}$ One modest step might be to restrict advertising that links drinking with masculinity ${ }^{64}$ or with liberation from traditionally feminine stereotypes. ${ }^{65}$ A more active strategy might be to use mass media and marketing methods to sell positive advantages of abstention or drinking in moderation, and not drinking in risky situations (eg, when driving or when pregnant). Such persuasion appears to work better when it involves personto-person contact, and when it aims to persuade drinkers that other people approve or disapprove of certain drinking behavior. ${ }^{66,67}$ Finally, persuasion to drink more moderately may be more effective if it comes from multiple sources in multiple parts of the community and government. . $^{6,69}$

Although it is essential to change popular beliefs that make drinking seem a privilege and symbol of gender equality to women, a badge of masculinity to men, and a license to engage in IPV, such changes by themselves are unlikely to reduce all the harm alcohol causes for women and men. It may also be necessary to make drinking more expensive, by strategies such as taxation and minimum price laws; and to make alcohol less available, through restrictions on where and when alcohol can be bought and sold. ${ }^{62}$ However, raising prices and reducing availability will be effective only if governments can also effectively reduce the sale and consumption of "unrecorded" (homemade, illicit, or surrogate) alcohol..$^{13}$

\section{Future directions}

This paper has summarized contributions of the GENACIS project in the areas of age-related drinking patterns, highrisk groups, alcohol and intimate partner violence, and social change and drinking. Future plans for the project include conducting follow-up surveys in at least four GENACIS countries: two in developing regions undergoing rapid social, economic, and gender-role change (Uganda and Karnataka state, India) and two in post-industrial societies (Denmark and US). The cross-national follow-up design was chosen to investigate changes in drinking patterns and related harms during the decade after the original GENACIS surveys. In addition to assessing alcohol-related harm to the drinker (eg, alcohol-related problems with the drinker's employment, relationships, or health), the follow-up surveys will focus on alcohol-related harms to other people (eg, violence or other injury, impaired family relationships, fetal alcohol effects). This focus on harm to others represents a major paradigm shift from past emphasis on harm to the drinker. It will substantially increase the estimated social costs of alcohol use ${ }^{70}$ and may suggest new targets for prevention and intervention. ${ }^{71}$ The follow-up surveys will permit tests of many of the predicted effects of social and gender-role change discussed in the preceding section. Analyses of existing and new data will be used to test emerging hypotheses about alcohol's harm to others, including women's risks of alcohol-exposed pregnancies and alcohol-related aggression affecting both genders. Increased attention will be given to associations between alcohol use and illicit drug use in existing and new surveys. The overarching goal of the GENACIS project, in its past and proposed future activities, is to enhance knowledge about how gender and culture influence alcohol use and related harms. Such knowledge, GENACIS members believe, can aid the development of more effective prevention, intervention, and policy to reduce the substantial global costs of alcohol and other substance abuse in both women and men.

\section{Acknowledgments}

Gender, Alcohol, and Culture: An International Study (GENACIS) is a collaborative international project affiliated 
with the Kettil Bruun Society for Social and Epidemiological Research on Alcohol and coordinated by GENACIS partners from the University of North Dakota (USA), Aarhus University (Denmark), the Alcohol Research Group/ Public Health Institute (USA), the Centre for Addiction and Mental Health (Canada), the AER Centre for Alcohol Policy Research/Turning Point Alcohol and Drug Centre (Australia), and the Addiction Info Switzerland Research Institute (Switzerland). Support for aspects of the project comes from the World Health Organization, the Quality of Life and Management of Living Resources Programme of the European Commission (Concerted Action QLG4-CT2001-0196), the US National Institute on Alcohol Abuse and Alcoholism/National Institutes of Health (Grants R21 AA012941 and R01 AA015775), the German Federal Ministry of Health, the Pan American Health Organization, and Swiss national funds. Support for individual country surveys was provided by government agencies and other national sources.

Preparation of this article was supported in part by Research Grant No. R01 AA015775 from the US National Institutes of Health National Institute on Alcohol Abuse and Alcoholism. The content is the sole responsibility of the author and does not necessarily represent the official views of the National Institute on Alcohol Abuse and Alcoholism or the National Institutes of Health. An earlier version of this paper was presented at the Fourth Meeting and Conference of the Women's International Group, Hollywood, FL, June 17, 2011.

\section{Disclosure}

The author has no conflicts of interests to declare in this research.

\section{References}

1. Torgrimson BN, Minson CT. Sex and gender: what is the difference? J Appl Physiol. 2005;99(3):785-787.

2. Wilsnack RW, Wilsnack SC, Klassen AD. Women's drinking and drinking problems: patterns from a 1981 national survey. Am J Public Health. 1984;74(11):1231-1238.

3. Wilsnack RW, Wilsnack SC, Kristjanson AF, Harris TR. Ten-year prediction of women's drinking behavior in a nationally representative sample. Women's Health. 1998;4(3):199-230.

4. Wilsnack RW, Kristjanson AF, Wilsnack SC, Crosby RD. Are US women drinking less (or more)? Aging and historical trends, 1981-2001. J Stud Alcohol. 2006;67(3):341-348.

5. Wilsnack SC, Klassen AD, Schur BE, Wilsnack RW. Predicting onset and chronicity of women's problem drinking: a five-year longitudinal analysis. Am J Public Health. 1991;81(3):305-318.

6. Kubička L, Csémy L, Kozený J. Prague women's drinking before and after the 'Velvet Revolution' of 1989: a longitudinal study. Addiction. 1995;90(11):1471-1478.
7. Spak L, Spak F, Allebeck P. Factors in childhood and youth predicting alcohol dependence and abuse in Swedish women: findings from a general population study. Alcohol Alcohol. 1997;32(3): 267-274.

8. Haavio-Mannila E, Harris TR, Klassen AD, Wilsnack RW, Wilsnack SC Alcohol and sexuality among American and Finnish women. Nordisk Sexologi. 1996;14:129-146.

9. Wilsnack RW, Vogeltanz ND, Wilsnack SC, Harris TR. Gender differences in alcohol consumption and adverse drinking consequences: cross-cultural patterns. Addiction. 2000;95(2):251-265.

10. Wilsnack SC, Wilsnack RW. International gender and alcohol research: recent findings and future directions. Alcohol Res Health. 2002;26:245-250.

11. Room R, Mäkelä K. Typologies of the cultural position of drinking. J Stud Alcohol. 2000;61(3):475-483.

12. Perez RL. Fiesta as tradition, fiesta as change: ritual, alcohol and violence in a Mexican community. Addiction. 2000;95(3):365-373.

13. Lachenmeier DW, Taylor BJ, Rehm J. Alcohol under the radar: do we have policy options regarding unrecorded alcohol? Int J Drug Policy. 2011;22(2)153-160.

14. Saunders J, Aasland O, Babor T, De la Fuente J, Grant M. Development of the Alcohol Use Disorders Identification Test (AUDIT): WHO Collaborative Project on Early Detection of Persons with Harmful Alcohol Consumption-II. Addiction. 1993;88(6):791-804.

15. World Bank. World development indicators. 2004. https://publications. worldbank.org/WDI/. Accessed April 15, 2008.

16. Hausman R, Tyson LD, Zahidi S. The Global Gender Gap Report 2006. Geneva: World Economic Forum; 2006.

17. Bloomfield $\mathrm{K}, \mathrm{Gmel} \mathrm{G}$, Wilsnack SC. Introduction to special issue 'Gender, Culture and Alcohol Problems: A Multi-national Study'. Alcohol Alcohol. 2006;41(Suppl 1):i3-i7.

18. Ólafsdóttir H, Greenfield TK. Editors' introduction. Drinking and informal social control: Five studies from Gender, Alcohol, and Culture: An International Study. Contemp Drug Probl. 2009; 36(1/2):7-12.

19. Obot IS, Room R, editors. Alcohol, Gender and Drinking Problems: Perspectives from Low and Middle Income Countries. Geneva, Switzerland: World Health Organization; 2005.

20. Graham K, Bernards S, Munné M, Wilsnack SC, editors. Unhappy Hours: Alcohol and Partner Aggression in the Americas. Washington, DC: Pan American Health Organization; 2008.

21. Graham K, Bernards S, Munné M, Wilsnack SC, editors. El brindis infeliz: El consumo de alcohol y la agresión entre parejas en las Américas. Washington, DC: Pan American Health Organization; 2010. Spanish.

22. Taylor B, Wilsnack SC, Rehm J. Gender, Alcohol, and Culture: An International Study (GENACIS): A brief history, present work, and future initiatives. In: Graham K, Bernards S, Munné M, Wilsnack SC, editors. Unhappy Hours: Alcohol and Partner Aggression in the Americas. Washington, DC: Pan American Health Organization; 2008:1-6.

23. Wilsnack RW, Wilsnack SC, Kristjanson AF, Vogeltanz-Holm ND, Gmel G. Gender and alcohol consumption: Patterns from the multinational GENACIS Project. Addiction. 2009;104(9):1487-1500.

24. Holmila M, Raitasalo K. Gender differences in drinking: why do they still exist? Addiction. 2005;100(12):1763-1769.

25. Wilsnack RW, Wilsnack SC, Obot IS. Why study gender, alcohol, and culture? In: Obot IS, Room R, editors. Alcohol, Gender and Drinking Problems: Perspectives from Low and Middle Income Countries. Geneva, Switzerland: World Health Organization; 2005:1-23.

26. Grant BF, Dawson DA, Stinson FS, Chou SP, Dufour MC, Pickering RP. The 12-month prevalence and trends in DSM-IV alcohol abuse and dependence: United States, 1991-1992 and 2001-2002. Drug Alcohol Depend. 2004;74(3):223-234.

27. Mäkelä P, Gmel G, Grittner U, et al. Drinking patterns and their gender differences in Europe. Alcohol Alcohol. 2006;41(Suppl 1):i8-i19. 
28. Jones AW. Evidence-based survey of the elimination rates of ethanol from blood with applications in forensic casework. Forensic Sci Int. 2010;200(1-3):1-20.

29. Kwo PY, Ramchandani VA, O'Connor S, et al. Gender differences in alcohol metabolism: relationship to liver volume and effect of adjusting for body mass. Gastroenterology. 1998;115(6):1552-1557.

30. Mumenthaler MS, Taylor JL, O’Hara R, Yesavage JA. Gender differences in moderate drinking effects. Alcohol Res Health. 1999; 23(1):55-64.

31. Rehm J, Taylor B, Mohapatra S, et al. Alcohol as a risk factor for liver cirrhosis: a systematic review and meta-analysis. Drug Alcohol Rev. 2010;29(4):437-445.

32. Wilsnack RW, Wilsnack SC. Introduction. In: Wilsnack RW, Wilsnack SC, editors. Gender and Alcohol: Individual and Social Perspectives. New Brunswick, NJ: Rutgers Center of Alcohol Studies; 1997:1-16.

33. Nghe LT, Mahalik JR, Lowe SM. Influences on Vietnamese men: examining traditional gender roles, the refugee experience, acculturation, and racism in the United States. J Multicult Couns Devel. 2003;31(4):245-261.

34. Willis J. 'Beer used to belong to older men': drinking and authority among the Nyakyusa of Tanzania. Africa. 2001;71(3):373-390.

35. Li Q, Wilsnack R, Wilsnack S, Kristjanson A. Cohabitation, gender, and alcohol consumption in 19 countries: a multilevel analysis. Subst Use Misuse. 2010;45(14):2481-2502.

36. Grittner U, Kuntsche S, Gmel G, Bloomfield K. Alcohol consumption and social inequality at the individual and country levels - Results from an international study. Under review, 2011.

37. Kuntsche S, Knibbe R, Gmel G. Social roles and alcohol consumption: a study of 10 industrialised countries. Soc Sci Med. 2009;68: 1263-1270.

38. Kuntsche S, Knibbe RA, Kuntsche E, Gmel G. Housewife or working mum-each to her own? The relevance of societal factors in the association between social roles and alcohol use among mothers in 16 industrialized countries. Addiction. 2011;106(11): 1925-1932.

39. Bloomfield K, Wicki M, Wilsnack S, Hughes T, Gmel G. International differences in alcohol use according to sexual orientation. Substance Abuse. 2011;32(4):210-219.

40. Graham K, Bernards S, Wilsnack SC, Gmel G. Alcohol may not cause partner violence but it seems to make it worse: a cross national comparison of the relationship between alcohol and severity of partner violence. J Interpers Violence. 2011;26(8):1503-1523.

41. Holmila M. Intimate partner violence and use of alcohol: A qualitative comparative study. Helsinki, Finland: Grant application to the Academy of Finland, funded May 2011.

42. Kubička L, Csémy L, Duplinsky J, Kozený J. Czech men’s drinking in changing political climates 1983-1993: a three-wave longitudinal study. Addiction. 1998;93(8):1219-1230.

43. Wilsnack SC. Social change and gendered drinking: A symposium in honour of Ludek Kubicka (Introduction). Addiction. 2005;100(12): 1760-1762.

44. Munné MI. Alcohol and the economic crisis in Argentina: Recent findings. Addiction. 2005;100(12):1790-1799.

45. Bloomfield K, Grittner U, Kramer S. Developments in alcohol consumption in reunited Germany. Addiction. 2005;100(12):1770-1778.

46. Wojtyniak B, Moskalewicz J, Stokwiszewski J, Rabczenko D. Genderspecific mortality associated with alcohol consumption in Poland in transition. Addiction. 2005;100(12):1779-1789.

47. Room R. Social change and gendered drinking: learning from differential changes in times of crisis. Addiction. 2005;100(12): 1800-1802.

48. Martinez P, Røislien J, Naidoo N, Clausen T. Alcohol abstinence and drinking among African women: data from the World Health Surveys. BMC Public Health. 2011;11:1-11.
49. Lee SH, Shin SJ, Won S-D, Kim E-J, Oh D-Y. Alcohol use during pregnancy and related risk factors in Korea. Psychiatry Investigation. 2010;7:86-92.

50. Bakke O, Endal D. Alcohol policies out of context: drinks industry supplanting government role in alcohol policies in sub-Saharan Africa. Addiction. 2010;105(1):22-28.

51. Benegal V, Nayak M, Murthy P, Chandra P, Gururaj G. Women and alcohol use in India. In: Obot IS, Room R, editors. Alcohol, Gender and Drinking Problems: Perspectives from Low and Middle Income Countries. Geneva, Switzerland: World Health Organization; 2005:89-123.

52. Tumwesigye NM, Kasirye R. Gender and the major consequences of alcohol consumption in Uganda. In: Obot IS, Room R, editors. Alcohol, Gender and Drinking Problems: Perspectives from Low and Middle Income Countries. Geneva, Switzerland: World Health Organization; 2005:189-208.

53. Hingson RW, Heeren T, Zakocs R, Kopstein A, Wechsler H. Magnitude of alcohol-related mortality and morbidity among US college students ages 18-24. J Stud Alcohol. 2002;63(2):136-144.

54. Spoth R, Greenberg M, Turrisi R. Preventive interventions addressing underage drinking: state of the evidence and steps toward public health impact. Pediatrics. 2008;121(Suppl 4):S311-S336.

55. Center for Substance Abuse Treatment. Substance abuse treatment: Addressing the specific needs of women. Treatment Improvement Protocol (TIP) Series 51. HHS Publication No. (SMA) 09-4426. Rockville, MD: Substance Abuse and Mental Health Services Administration; 2009:127-130.

56. Anderson P. Time for the middle aged to own up to the problem. Addiction. 2009;104(9):1501-1502.

57. Rogers EM. Diffusion of Innovations. 5th ed. New York: Free Press; 2003.

58. Drabble L, Midanik LT, Trocki K. Reports of alcohol consumption and alcohol-related problems among homosexual, bisexual, and heterosexual respondents: Results from the 2000 National Alcohol Survey. J Stud Alcohol. 2005;66(1):111-120.

59. Wilsnack SC, Hughes TL, Johnson TP, et al. Drinking and drinkingrelated problems among heterosexual and sexual minority women. J Stud Alcohol Drugs. 2008;69(1):129-139.

60. Wilsnack SC, Wilsnack RW. General issues in research on intimate partner violence: An overview. In: Graham K, Bernards S, Munné M, Wilsnack SC, editors. Unhappy hours: Alcohol and Partner Aggression in the Americas. Washington, DC: Pan American Health Organization; 2008:7-24.

61. Mitchell T. Intoxicated Identities: Alcohol's Power in Mexican History and Culture. London, UK: Routledge; 2004.

62. Babor T, Caetano R, Casswell S, et al. Alcohol: No Ordinary Commodity. 2nd ed. New York: Oxford University Press; 2010 .

63. Wilkinson C, Room R. Warnings on alcohol containers and advertisements: international experience and evidence on effects. Drug Alcohol Rev. 2009;28:426-435.

64. Strate L. Beer commercials: A manual on masculinity. In: Craig S, editor. Men, Masculinity and the Media. London, UK: Sage Publications; 1992:78-92.

65. Kilbourne J. Deadly Persuasion: Why Women and Girls Must Fight the Addictive Power of Advertising. New York: Free Press; 1999.

66. Larimer ME, Cronce JM. Identification, prevention, and treatment revisited: individual-focused college drinking prevention strategies 1999-2006. Addict Behav. 2007;32(11):2439-2468.

67. Moreira MT, Smith LA, Foxcroft D. Social norms intervention to reduce alcohol misuse in university or college students. Cochrane Database Syst Rev. 2009;(3):CD006748.

68. Holder HD, Gruenewald PJ, Ponicki WR, et al. Effect of communitybased interventions on high-risk drinking and alcohol-related injuries. JAMA. 2000;284(18):2341-2347. 
69. Khaikaew S, Hoontrakul S, Punsakd W, Ucharattana P, Rungsang V. Empowering individuals, families, and communities for the prevention, reduction, and withdrawal of alcohol abuse. Asian J Nurs. 2008;11: 36-40.

70. Laslett A-M, Room R, Ferris J, Wilkinson C, Livingston M, Mugavin J. Surveying the range and magnitude of alcohol's harm to others in Australia. Addiction. 2011;106(9):1603-1611.
71. Room R, Ferris J, Laslett A-M, Livingston M, Mugavin J, Wilkinson C. The drinker's effect on the social environment: a conceptual framework for studying alcohol's harm to others. Int J Environ Res Public Health. 2010;7(4):1855-1871.

Substance Abuse and Rehabilitation

\section{Publish your work in this journal}

Substance Abuse and Rehabilitation is an international, peer-reviewed, open access journal publishing original research, case reports, editorials, reviews and commentaries on all areas of addiction and substance abuse and options for treatment and rehabilitation. The manuscript management system is completely online and includes a very quick and fair peer-review system. Visit http://www.dovepress.com/testimonials.php to read real quotes from published authors. 